\title{
ESTRESSE OCUPACIONAL DA ENFERMEIRA DE CENTRO DE MATERIAL
}

\author{
Arlete Silva* \\ Estela Regina Ferraz Bianchi**
}

SILVA, A.: BIANCHI, E. R. F. Estresse ocupacional da enfermeira de centro de material.

Rev. Esc. Enf. USP, v. 26, n. 1, p. 65-74, mar. 1992.

Este estudo tem por objetivos caracterizar a enfermeira que atua na Unidade de Centro de Material, verificar quais as atividades que desenvolvem e consideram geradoras de desgaste emocional significativo e propor medidas para a minimização das fontes de estresse. A população constituiu-se de 8 (oito) enfermeiras com idade entre 25 a 30 anos, que trabalham em UCM há menos de 5 anos e se consideram satisfeitas com a sua atuação nessa unidade. Foi considerada a área administrativa a maior fonte de estresse. Um passo importante para a minimização do estresse gerado nessa unidade, seria o reconhecimento.

UNITERMOS: Estresse, Centro de Material e esterilização em hospital.

\section{INTRODUÇÃO}

Todo indivíduo, ao necessitar de assistência hospitalar, pode ser surpreendido por uma infecção, em consequiência de vários fatores, entre eles, da própria patologia que o acomete, do seu estado nutricional e dos métodos de diagnóstico e tratamento invasivos.

É uma preocupação constante dos profissionais de saúde encontrar medidas de controle da infeç̧ão hospitalar. ANGERAMI \& BOEMER ${ }^{1}$ consideram como função do Serviço de Enfermagem a maioria dos aspectos práticos do controle de infecção e acrescentam que "como a enfermeira é a única pessoa no hospital que fica em contacto com o paciente todas as horas do dia e da noite, somente ela pode exercer uma contínua supervisão no que diz respeito ao controle de infecções".

Os materiais hospitalares utilizados nos inúmeros procedimentos contribuem de maneira significativa para elevar o nível de infecção hospitalar, quando não são preparados adequadamente, tanto em quantidade como em qualidade.

\footnotetext{
* Enfermeira. Assistente do Departamento de Enfermagem Médico-Cirúrgica da EEUSP - disciplina Enfermagem em Centro-Cirúrgico. Mestre em Enfermagem.

* Enfermeira. Doutor do Departamento de Enfermagem Médico-Cirúrgica da EEUSP - disciplina Enfermagem em Centro-Cirúrgico.
} 
A unidade de Centro de Material (UCM) é a unidade responsável pelo processamento de todo o material, de forma a prover materiais a todas as unidades do hospital, na qualidade, quantidade e em condições adequadas para uso, para promover uma assistência segura e eficaz ao paciente.

Infelizmente, temos que concordar com PERKINS ${ }^{10}$ quando afirma que na maioria das vezes a UCM é relegada a segundo plano, não sendo reconhecida como uma unidade importante no contexto hospitalar.

Isto pode ser observado pelas condições, nem sempre adequadas dessa unidade, para o desenvolvimento de suas atividades, condições essas de ambiente físico, recursos humanos e materiais. $O$ ambiente físico, com algumas excessōes, é improvisado, acamado, sem espaço suficiente e sem possibilidade de estabelecer um fluxo adequado de pessoal e material.

O ambiente físico da UCM deve ser planejado para oferecer conforto e segurança aos funcionários no desenvolvimento de suas atividades, além de propiciạr um tratamento adequado ao material que ali é processado.

O processamento dos materiais deve obedecer um fluxo progressivo e linear, sem cruzamento; nesse sentido, são consideradas quatro áreas distintas dentro da UCM: recebimento e limpeza do material usado, preparo e acondicionamento, esterilização e guarda e distribuição do material esterilizado.

Podemos afirmar que a UCM é uma área insalubre pois o risco à saúde das pessoas que ali trabalham é muito grande, seja pelo manuseio dos materiais contaminados, pela inalação de talco quando no preparo de luvas, pela inalação de gases esterilizantes; pela manipulação de agentes desinfetantes, pela temperatura elevada na área de esterilização e ainda por ser um ambiente fechado.

Podemos observar que além dos aspectos anteriormente mencionados, a falta de contacto direto com o paciente, é um fato para que muitos funcionários rejeitem o trabalho na UCM ou até que não tenham motivação para ali atuarem. Outro fator coadjuvante é a repetitividade das atividades diárias, tornando-se um trabalho rotineiro, monótono e, na maioria das vezes, não valorizado pelos colegas de outras unidades e também pelos outros membros da equipe de saúde.

Entretanto, o centro de material é uma unidade onde qualquer falha ocorrida pode acarretar ônus ao paciente, à instituição e à equipe multiprofissional.

O funcionário do UCM é uma pessoa que deve estar consciente de sua responsabilidade na prestação de assistência ao paciente. Na maioria das vezes é um atendente de enfermagem, que está sob supervisão de uma enfermeira e para o desempenho de sua funções é exigido treinamento e educação contínua.

$O$ estresse tem sido alvo de estudos em diversas esferas de conhecimento. Adotamos o referencial teórico de LAZARUS \& LAUNIER $^{8}$ que definem estresse como "qualquer evento que demande do ambiente interno ou externo e que taxe ou exceda as fontes de adaptação de um indivíduo, sistema social ou tissular".

Nesta visão interacionista de estresse, consideramos que a UCM pode ser um local de trabalho estressante para a enfermeira, pois é um ambiente que demanda adaptação individual, grupal e que exige liderança do profissional para enfrentar problemas de recursos humanos e materiais ali existentes. 
Há estudos comprovando que a enfermagem é uma profissão estressante por conviver com doentes, morte, sofrimento e dor $\left(\right.$ MENZIES $\left.^{9}\right)$. Na UCM essa situação não existe, mas existe sim, uma pessoal que desenvolve atividades técnicas, com urgência na quantidade e rigor na qualidade do material a ser utilizado nas diversas unidades. Para MENZIES ${ }^{9}$ são variáveis acumuladas ao estresse o desempenho somente de atividade técnicas, a falta de espaço para tomada de decisão e a resistência a mudanças.

LAETT \& SCHNECK ${ }^{7}$ e GRAY-TOFT \& ANDERSON ${ }^{4}$ advertem que o estresse está também relacionado às unidades em que se atua e às atividades desempenhadas.

Baseadas nessa situação, realizamos o presente estudo, com os seguintes objetivos:

1. Caracterizar a enfermeira que atua na UCM;

2. Verificar as atividades consideradas estressantes pelas enfermeiras de centro de material quanto à atuação nessa unidade;

3. Propor medidas a nível de atuação, para diminuir ou eliminar as fontes de estresse na UCM.

\section{MATERIAL E MÉTODO}

\section{População}

Foi pesquisada uma amostra de 8 (oito) enfermeiras da UCM que participaram da reunião mensal do mês de maio de 1986, do Grupo de Enfermagem em Centro Cirúrgico da ABEn-SP. Essa amostra representa a participação de sete instituiçōes hospitalares diferentes ao Município de São Paulo.

\section{Coleta de dados}

Utilizou-se um questionário com perguntas abertas e fechadas para caracterizar a amostra e para verificar as atividades que a enfermeira executa na UCM e quais as que considera estressantes.

Esse questionário foi distribuído às enfermeiras presentes na reunião e foi recolhido no mesmo dia.

\section{Tratamento dos dados}

Os dados obtidos foram agrupados manualmente e foi feito tratamento percentual. Serão apresentados em tabelas ou quadros quando houver necessidade de evidenciar o resultado.

\section{III - RESULTADOS E DISCUSSĀO}

\section{Caracterização da amostra}

A amostra foi constituída de mulheres com idade, em sua maioria $(62,5 \%)$, entre 25 e 30 anos; tendo terminado o curso de Graduação em Enfermagem de 
1 a 5 anos $(50,0 \%)$. A maioria $(75,0 \%)$ não optou por trabalhar na UCM, sendo que $4(50,0 \%)$ enfermeiras trabalham nessa área de 1 a 5 anos.

Deve-se ressaltar o fato de $75,0 \%$ da amostra não ter optado por trabalhar na UCM. Como já foi explicado, o trabalho nessa área pode ser considerado monótono e sem incentivo, numa visão não muito profunda da importância das atividades desenvolvidas nessa área. Se a enfermeira não faz a opção por trabalhar nesse setor, pode ser considerado um fator agravante para a ocorrência de estresse. Para $\mathrm{GAY}^{3}$ o estresse pode surgir pela experiência negativa que a pessoa tem ao se defrontar com o ambiente.

Ao se perguntar o motivo pelo qual essas enfermeiras não optaram mas estão trabalhando na UCM, obtivemos: $2(33,3 \%)$ responderam que ao supervisionar o centro cirúrgico, o centro de material era uma unidade anexa à sua atuação; $2(33,3 \%)$ foram escaladas para a UCM; $1(16,6 \%)$ foi convidada a trabalhar na unidade mesmo sem experiência e $1(16,6 \%)$ não revelou o motivo.

Os motivos que levaram as duas enfermeiras optarem por trabalhar na UCM foram: uma não gostava das outras áreas oferecidas e a outra, pelo fato do centro de material ser uma unidade que oferecia oportunidade para aprender, mesmo sem experiência anterior.

Neste estudo, o que se verificou foi que a maioria, $6(75,0 \%)$ enfermeiras está satisfeita com sua atuação na UCM. Foram citados como motivos, os relacionados no quadro 1.

Quadro 1: Motivos de satisfação das enfermeiras quanto a atuação na UCM.

— área de grande interesse, campo amplo de estudo, de novidades, com oportunidade para implantar rotinas

- área de desenvolvimento do potencial da enfermeira, sem influência de outros profissionais

— área de atuação nos aspectos administrativos

- serviço de alta responsabilidade e tão importante quanto a assistência direta ao paciente

- sempre obteve colaboração e gosta da área

* 1 não respondeu

Em contrapartida, as $2(25,0 \%)$ enfermeiras que não estão satisfeitas com o trabalho uma prefere o contacto direto com o paciente e a outra percebe a atuação nesse setor como não devidamente valorizada.

A insatisfação no trabalho reflete a ação da pessoa no desenvolvimento de suas atividades, o que além de levar ao desânimo, à falta de interesse, também 
pode acarretar o estresse, e até chegar à desistência da profissão, como última consequiência da situação.

\section{Atividades desenvolvidas na UCM}

A maioria das enfermeiras, $7(87,5 \%)$ não atuam somente na UCM, sendo que: $4(57,1 \%)$ respondem também pelo centro cirúrgico; $2(28,6 \%)$ pelo centro cirúrgico e sala de recuperaçào anestésica e $1(14,3 \%)$ pelo pronto socorro.

As atividades desempenhadas pela enfermeira na UCM foram agrupadas em administrativas e técnicas, como pode-se verificar nas tabelas 1 e 2 .

Tabela 1: Distribuição das atividades, na área de administração, relatadas pelas 8 enfermeiras da UCM. São Paulo, 1986.

\section{ATIVIDADES}

№ \%

- supervisão e coordenação

520,0

- compra de instrumental, material de consumo e aparelhos

312,0

- solicitação de revisão e consertos de aparelhos

210,8

- orientação e treinamento específico de funcionários

210,8

- reposição de material de consumo

14,0

- levantamento bimestral de material existente nas unidades

14,0

- relação de material a ser enviado à esterilização por óxido de etileno

14,0

- planejamento de caixa cirúrgica

14,0

- controle de extravios e perda de instrumentos

14,0

- controle de material novo

14,0

- controle de qualidade do serviço prestado

14,0

- teste de material a ser adquirido

14,0

- teste de material de uso

14,0

- escala de folga

14,0

- escala de atividades de funcionários

14,0

- relatório mensal

14,0

- reunião bimensal com funcionários

14,0

TOTAL

25100,0 
Tabela 2. Distribuição das atividades na área técnica, relatadas pelas 8 enfermeiras da UCM. São Paulo, 1986.

\section{ATIVIDADES}

№ \%

— teste bacteriológico de aparelhos

433,3

- preparo de material

216,6

- preparo de caixa cirúrgica

216,6

- manuseio de aparelhos

18,3

- desenvolvimento de técnicas diárias

18,3

- entrega de material

18,3

— esterilização

18,3

TOTAL

12100,0

Pode-se verificar que a maioria das atividades mencionadas pelas enfermeiras da UCM estárelacionada à área de administração. Entre elas, a supervisão e coordenação representa $20,0 \%$ das atividades dessa área o que é condizente com sua atuação como líder da equipe de enfermagem desse setor. Esse resultante é coincidente ao obtido por SALZANO ${ }^{12} \mathrm{em}$ seu estudo sobre as atividades das enfermeiras da UCM.

\section{Atividades consideradas estressantes}

As enfermeiras citaram lagumas atividades estressantes e que consideram causadoras de desgaste emocional significativo, como pode-se verificar na tabela 3 .

Tabela 3. Distribuição das atividades consideradas estressantes pelas enfermeiras da UCM. São Paulo, 1986.

ATIVIDADES

№ \%

- acúmulo de material a ser preparado em curto prazo

211,7

- aparelhos com defeito

211,7

- controle de estoque de material descartável

15,9

- preparo de material especializado

15,9

- planejamento de caixa cirúrgica sem auxílio de cirurgião

15,9 
- planejamento de custos sem metas conhecidas

- esterilização de material sem tempo hábil

- falta de roupa para desenvolver técnica

— falta de material na hora certa

- solicitações intensas das unidades

- dificuldade em conseguir manutenção imediata de aparelhos

- ambiente (número de aparelhos, ruído elevado, calor excessivo, setor fechado)

— supervisão

- conscientização do funcionário quanto à importância e responsabilidade das técnicas

- atividade técnica sem participação efetiva do enfermeiro e motivação do grupo para manter a qualidade do material preparado

\section{TOTAL $17 \quad 100,0$}

Pode-se verificar que as atividades consideradas estressantes pela enfermeiras da UCM estão relacionadas à área de administração: previsão, provisão, planejamento, controle e avaliação. Este resultado é esperado pois, como foi demonstrado, a enfermeira da UCM tem maior sobrecarga no desempenho das atividades dessa área, o que acarreta maior estresse.

Num estudo de CASSEM \& HACKETT ${ }^{2}$, pioneiros em pesquisar os estressores na atuação da enfermeira, verificaram que a enfermeira de unidade de terapia intensiva é estressada, sendo as principais fontes de estresse a administração dessa unidade, a escala de plantões e o relacionamento humano.

Este trabalho é importante para o estudo do estresse ocupacional da enfermeira de UCM pois, mesmo numa unidade onde o contato direto com o paciente é realizado minuto a minuto, o estressor apontado foi a área administrativa. No presente estudo, também a administração da UCM foi citada como estressor, num ambiente em que o contato direto com o paciente é praticamente nulo. Isto faz surgir em questionamento: será que as enfermeiras não têm dificuldades no âmbito administrativo, independente da área de atuação, sendo um estressor inerente ao trabalho dessa profissional?

Outro fator que deve-se ressaltar é a pressão do tempo que foi mencionado 3 vezes (acúmulo de material a ser preparado em curto prazo - 2; esterilização de material sem tempo hábil - 1) Em pesquisa realizadas sobre o estresse, 
a pressão do tempo é um fator desgastante e que gera tensão, sendo uma fonte poderosa de estresse, como foi verificado por LEATT \& $\mathrm{SCHNECK}^{6}$ na pesquisa junto a enfermeiras de diferentes especialidades.

O equipamento e material são dois fatores que geram estresse para a enfermeira da UCM. Como foi observado por STEPPEN ${ }^{13}$, o equipamento quando está funcionando corretamento nāo produz ansiedade, mas é uma fonte de estresse quando está funcionando mal.

HEWITT ${ }^{s}$ e PRESTON et alii" ${ }^{11}$ em seus estudos sobre o centro cirúrgico, descrevem os fatores estressantes nessa unidade e alguns deles podemos relacionar à UCM: a alta tecnologia empregada; a dificuldade em realizar previsão e provisão de material e equipamento com orçamento restrito; isolamento na unidade; pouco contacto pessoal com o paciente; sobrecarga de trabalho e pressão de tempo.

Acreditamos que grande parte desses fatores considerados estressantes podem ser diminuidos ou eliminados, se a enfermeira que atua na UCM contar com algumas condições para o desenvolvimento de suas atividades.

A administração do hospital deve ser sensibilizada para a importância e adequadação da UCM no contexto geral da instituição e cabe a nós, enfermeiras que vivenciamos toda essa problemática, lutarmos para a obtenção dessa condições.

Com um efetivo entrosamento da enfermeira da UCM com as enfermeiras das unidades de internação e com os demais serviços de apoio, pode-se diminuir ou até mesmo sanar, o problema da falta de tempo hábil para se proceder a esterilização dos materiais e até mesmo a falta de diversos materiais, e manutenção e conserto dos aparelhos, preparo de material especializado e montagem de caixas de instrumental cirúrgico, fatores considerados estressantes pelas enfermeiras do presente trabalho.

A realização de reuniōes periódicas com a equipe de enfermagem da UCM é uma dinâmica que cada vez mais está sendo implementada com os objetivos de troca de experiência, de discussão de aspectos positivos e negativos do trabalho realizado nessa unidade, proporcionando oportunidade de diminuição de estresse, a participação efetiva do pessoal envolvido e a resolução de problemas.

Só através da luta constante é que se obterá melhores condições de trabalho e a consequente eliminação ou diminuição do estresse ocupacional dessa área.

\section{CONCLUSÕES}

De acordo com os dados obtidos neste estudo, podemos concluir que:

- a enfermeira da UCM é do sexo feminino, com idade entre 25 e 30 anos $(62,5 \%)$ e com 1 a 5 anos $(50,0 \%)$ de formada. Na sua maioria $(75,0 \%)$, não optaram para trabalhar nessa áea, mas apesar disso estão satisfeitras pelo desempenho de suas funcões nesse local.

- quanto às atividades consideradas estressantes pelas enfermeiras da UCM, podemos destacar entre outras: o curto prazo de tempo para o preparo e esterilização de material $(11,7 \%)$; aparelhos com defeito sem manutenção imediata $(11,7 \%)$; solicitações constantes das unidades $(5,9 \%)$; planejamento de cus- 
tos, sem conhecimento das metas $(5,9 \%)$; planejamento de caixas cirúrgicas sem auxílio do cirurgião (5,9\%); falta de material para o desempenho de atividades $(5,9 \%)$.

- como medidas a nível de atuação, para eliminar ou diminuir o estresse da enfermeira da UCM propomos:

* sensibilização da administração do hospital para considerar a UCM como uma unidade vital na assistência prestada ao cliente, e fornecer subsídios e condiçōes para um eficaz desenvolvimento do trabalho nessa unidade;

* o entrosamento efetivo com unidades de internação e serviços afins;

* educação continuada e reuniōes periódicas da equipe de enfermagem da UCM;

* um trabalho consciente e responsável para mostrar que todos devem dar a devida valorização do serviço ali desenvolvido.

SILVA, A.; BIANCHI, E.R.F. Stress in nurses of central supply unit. Rev. Esc. Enf. USP, v. 26, n. 1, p. 65-74, mar. 1992.

The goals of this study were to characterize the central supply nurses to verify the nursing activities that are involved in occupational stress, and to lessen the stressors. Eight nurses comprised the sample; they were 25 to 30 years old, worked in the unit less than 5 years and they were satisfied with their job. The administrative area were the most mencioned stressor. The recognition and valorization of central suplly area is an important aspect to diminish thje nurses stress.

UNITERMOS: Stress: central supply hospital

\section{REFERENCIAS BIBLIOGRÁFICAS}

01. ANGERAMI, E. L.; BOEMER, M.R. Análise bacteriológica de amostras urina coletadas com técnicas distintas. Enf. Novas Dimens., v. 2, n. 1, p. 28-33, 1976.

02. CASSEM, N.H.; HACKETT, T.P. Sources of tension for the CCU nurse Amer. J. Nurs., v. 72 , n. 8, p. $1426-30,1972$.

03. GAY, J.E. Nursing under stress. Occup. Health, v. 37, n.4, p. 179-83, 1985.

04. GRAY-TOF, P.; ANDERSON, J.G. The nursing stress scale: development of a instrument. J.Behav. Assess, v. 3, n. 1, p. 11-23, 1981.

05. HEWITT, D. W. OR stress: how to get it, how to keep it, how to lose it. Today's OR nurse, v. 2, n. 8, p. 9-14, 1980.

06. LEATT, P.; SCHNECK, R. Differences in stress perceived by head nurses across nursing specialities in hospitals. J. Adv. Nurs.. v. 5, n. 1, p. 31-46, 1980.

07.

Perceptions of stress by nursing in different specilities: some implications of nursing administrators Nurs. Pap., v. 15, n. 4, p. 19-33, 1983.

08. LAZURUS, R.S.: LAUNIER, R. Stress-related transaction between person and enviromment. In: DERVIN, L.A.; LEWIS. M. Perspectives in international psychology. New York, Plenum, 1978. p. 287-327. 
09. MENZIES, I.E. Nurses under stress. Int. Nurs. Review, v. 7, n. 6, p. 9-16, 1960.

10. PERKINS, J.J. Principles and methods of sterilization in bealth sciences. 3. ed. Springfield, Charles C. Thomas, 1981.

11. PRESTON, C.A. et alii. Stress and the O.R. Nurse. AORN J., v. 33, n. 4, p. 662-71, 1981.

12. SALZANO, S.D.T. Atividades das enfermeiras de centro de material e suas expectativas quanto ao ensino de enfermagem nesta área, em nível de graduaçāo. Rev. Bras. Enf., v. 38, n. 1, p. 26-31, 1985.

13. STEPPEN, S.M. Perspections of stress: 1800 nurses tell their stories. In: CLAUS, K.E.; BAILEY, J.T. Living with stress and promoting well-being: a handbook for nurses. Saint Louis, Mosby, 1980. cap. 6 , p. $38-58$. 